\title{
Studies on the sand fly fauna (Diptera: Psychodidae) in high-transmission areas of cutaneous leishmaniasis in the Republic of Suriname
}

\author{
Alida D Kent ${ }^{*}$, Thiago V Dos Santos ${ }^{2}$, Anielkoemar Gangadin ${ }^{3}$, Ashok Samjhawann ${ }^{4}$ Dennis R A Mans ${ }^{5}$ \\ and Henk D F H Schallig ${ }^{6}$
}

\begin{abstract}
Background: Sand flies (Diptera: Psychodidae) are the vectors of Leishmania parasites, the causative agents of leishmaniasis. Cutaneous leishmaniasis is an increasing public health problem in the Republic of Suriname and is mainly caused by Leishmania (Vianna) guyanensis, but L. (V.) braziliensis, L. (L.) amazonensis, and L. (V.) naiffi also infect humans. Transmission occurs predominantly in the forested hinterland of the country. Information regarding the potential vectors of leishmaniasis in Suriname is limited. This study aims to broaden the knowledge about vectors involved in the transmission of cutaneous leishmaniasis in Suriname. For this purpose, sand flies were characterized in various foci of cutaneous leishmaniasis in the country, the districts of Para, Brokopondo, and Sipaliwini.

Methods: Sand flies were collected in areas around mining plots and villages using CDC light traps in the period between February 2011 and March 2013. They were categorized by examination of the spermathecea (females) and the external genitalia (males).

Results: A total of 2,743 sand fly specimens belonging to 34 different species were captured, including four species (Lutzomyia aragaoi, Lu. ayrozai, Lu. damascenoi, and Lu. sordellii) that had never before been described for Suriname. Five percent of the catch comprised Lu. squamiventris sensu lato, one female of which was positive with $L$. (V.) braziliensis and was captured in a gold mining area in Brokopondo. Other sand fly species found positive for Leishmania parasites were Lu. trichopyga, Lu. ininii, and Lu. umbratilis, comprising 32, 8, and 4\%, respectively, of the catch. These were captured at gold mining areas in Brokopondo and Sipaliwini, but the Leishmania parasites they had ingested could not be identified due to insufficient amounts of DNA.

Conclusions: The sand fly fauna in Suriname is highly diverse and comprises Lutzomyia species capable of transmitting Leishmania parasites. Four new Lutzomyia species have been found, and four species - Lu. squamiventris (s.l.), Lu. trichopyga, Lu. ininii, and Lu. umbratilis - have been found to harbor Leishmania parasites. The latter were among the most abundant species captured. These observations may contribute to the understanding of leishmaniasis transmission and the development of control programs in Suriname.
\end{abstract}

Keywords: Sand fly species, Lutzomyia, Leishmania, Suriname

\footnotetext{
* Correspondence: alipeace3@gmail.com

${ }^{1}$ Department of Parasitology, Faculty of Medical Sciences, Anton de Kom

University of Suriname, Kernkampweg 5, Paramaribo, Suriname

Full list of author information is available at the end of the article
} 


\section{Background}

Leishmaniasis is a parasitic disease caused by protozoan flagellates of the genus Leishmania. It is encountered in eighty-eight tropical and sub-tropical countries throughout the world where it mainly affects poor communities, and has a worldwide prevalence of 12 million cases [1]. Transmission is via the bite of infected female sand flies (Diptera: Psychodidae) of the genus Phlebotomus in the Old World or the genus Lutzomyia in the New World [2]. There are various clinical manifestations of leishmaniasis, the most common of which are the cutaneous and visceral forms. The cutaneous type ranges from single, self-limiting skin ulcers to more disseminated forms with disfiguring scar formation [3]. The visceral type affects internal organs such as spleen, liver, and bone marrow, and patients with this form usually suffer from fever, weight loss, and an enlarged spleen and liver $[4,5]$.

The Republic of Suriname has a surface area of $163,820 \mathrm{~km} 2$, is situated on the north-east coast of South America, and borders the Atlantic Ocean to the north, French Guiana to the east, Brazil to the south, and Guyana to the west (Figure 1). Roughly $80 \%$ of the population of about 530,000 lives in the urban-coastal area comprising the capital city of Paramaribo and the Wanica district located in the narrow low-land coastal zone in the northern part of the country (Figure 1). The rural-coastal area of Suriname comprises the districts of

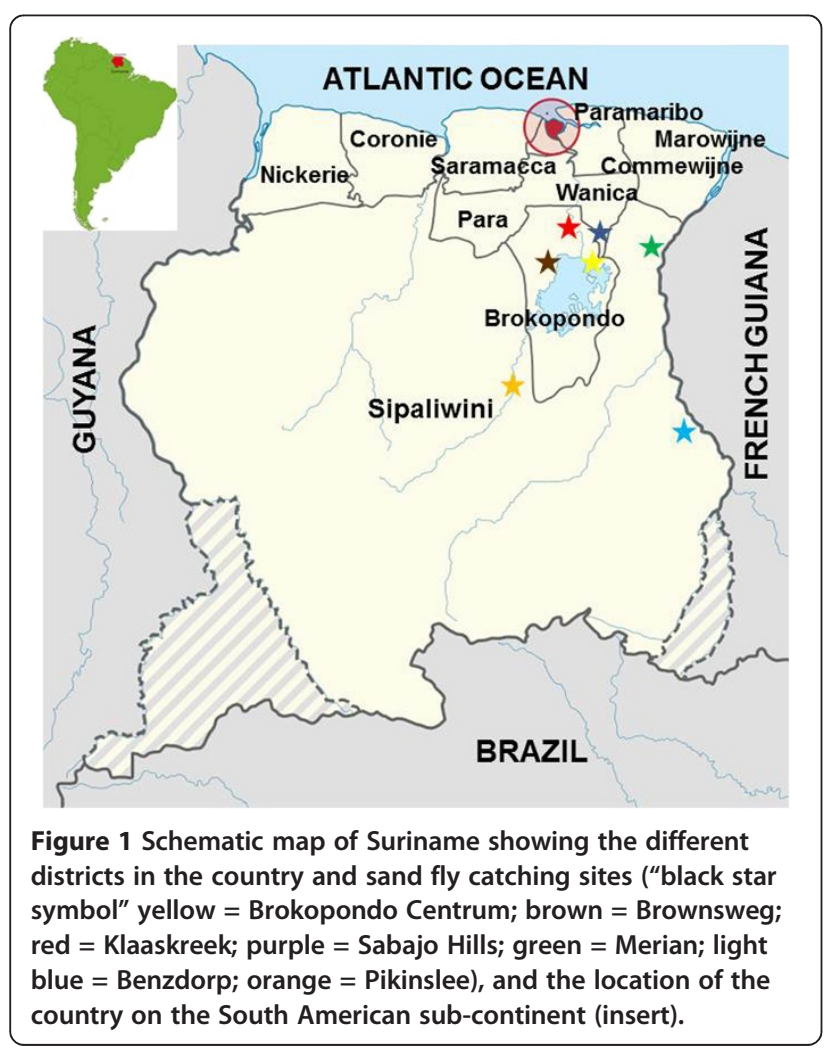

Marowijne, Commewijne, Saramacca, Coronie, and Nickerie (Figure 1), and is, together with the southern-rural interior consisting of the districts of Para, Brokopondo, and Sipaliwini (Figure 1), home to the remaining 20\% of Suriname's inhabitants.

The latter part of the country (the hinterland) comprises more than three-quarters of its land surface, and consists largely of sparsely inhabited savanna and dense tropical rain forest. It is mainly populated by Maroons and Amerindians who live in villages along the major rivers. It is also the part of the country with extensive gold mining, bauxite mining, logging, and ecotourism activities that have been growing in scale and economic importance in recent years [6]. Suriname has a tropical climate with abundant rainfall, a uniform temperature of on average $27^{\circ} \mathrm{C}$, and a relative humidity of $81 \%$ in Paramaribo [7]. There are four seasons, namely the long rainy season (April-July), the long dry season (AugustNovember), the short rainy season (December-January), and the short dry season (February-March).

Cutaneous leishmaniasis is an emerging disease in Suriname where it is known as 'bosyaws' or 'busiyasi' [8]. In this country, cutaneous leishmaniasis is endemic, with a zoonotic cycle in which the sand fly vector is in close relationship with the parasites and their wild mammalian reservoir hosts [9]. This cycle takes place primarily in the forested interior of the country where most of the infections occur, and people are most likely to be infected when they intrude in the vectors' habitat. The Dermatology Service, a division of Suriname's Ministry of Health that is responsible for the majority of patients with cutaneous leishmaniasis, has reported an increase in the number of cases from 139 to 280 between the years 2006 and 2011 [unpublished data]. This upsurge has been attributed to a higher risk of exposure to the vectors as a result of the above-mentioned increase in economic activities in the hinterland [6].

The majority of cutaneous leishmaniasis cases in Suriname (95.8\%) has been attributed to infection with Leishmania (Vianna) guyanensis [6]. So far, the sand fly vector that transmits this disease in the country is unknown. A possible candidate is Lutzomyia umbratilis [10], the proven vector of $L$. (V.) guyanensis in other countries of the Amazon basin $[9,11]$, and this sand fly species is also present in Suriname [10]. In addition, other Leishmania species have recently been identified in Suriname, including $L$. (V.) lainsoni and $L$. (L.) amazonensis [12], L. (V.) naiffi [13], as well as L. (V.) braziliensis [14]. The sand fly species transmitting these Leishmania species have also been identified in other Amazonian countries, but not in Suriname $[9,15]$.

In view of the increasing prevalence of cutaneous leishmaniasis in the country, and considering the ability of L. (L.) amazonensis and L. (V.) braziliensis to cause 
the more serious muco-cutaneous form of the disease, it is important to characterize the sand fly species responsible for the transmission of leishmaniasis in Suriname. For this reason, the sand fly diversity in various foci of cutaneous leishmaniasis in the interior of Suriname has been assessed in the present study. The results obtained may improve the understanding of leishmaniasis transmission in the country and contribute to the development of control programs.

\section{Methods}

\section{Collection sites}

Sand flies were collected between February 2011 and March 2013 in the forested hinterland of Suriname. The collection sites were selected on the basis of cases of cutaneous leishmaniasis reported by the Dermatology Service and the Medical Mission. The latter institution is also a division of Suriname's Ministry of Health and provides primary health care in the hinterland.

The collection sites were grouped according to their locations in the different administrative districts. In the southern district of Sipaliwini (Figure 1), three places were surveyed, the gold mining village of Benzdorp $\left(03^{\circ} 40^{\prime} 8^{\prime \prime} \mathrm{N}, 54^{\circ} 5^{\prime} 8^{\prime \prime} \mathrm{W}\right)$ in November 2010 and March 2013, the Maroon village Pikinslee $\left(04^{\circ} 15^{\prime} 17^{\prime \prime} \mathrm{N}, 55^{\circ} 26^{\prime}\right.$ $15^{\prime \prime} \mathrm{W}$ ) in April 2012, and the gold mining area of Merian $\left(5^{\circ} 4^{\prime} 26^{\prime \prime} \mathrm{N}, 54^{\circ} 29^{\prime} 47^{\prime \prime} \mathrm{W} ; 5^{\circ} 6^{\prime} 16^{\prime \prime} \mathrm{N}, 54^{\circ} 31^{\prime} 2^{\prime \prime} \mathrm{W} ; 5^{\circ} 5^{\prime} 24^{\prime \prime}\right.$ $\left.\mathrm{N}, 54^{\circ} 31^{\prime} 59^{\prime \prime} \mathrm{W}\right)$ in February 2013. In the centrally located Brokopondo district (Figure 1), gold mining plots in the vicinity of Brokopondo Centrum (05 $1^{\prime} 25^{\prime \prime} \mathrm{N}, 54^{\circ} 59^{\prime} 33^{\prime \prime}$ W) in February 2011, gold mining plots in the vicinity of the Maroon village Klaaskreek $\left(05^{\circ} 10^{\prime} 50^{\prime \prime} \mathrm{N}, 55^{\circ} 4^{\prime} 47^{\prime \prime} \mathrm{W}\right)$ in April 2011), and Maroon villages around Brownsweg $\left(05^{\circ} 0^{\prime} 56^{\prime \prime} \mathrm{N}, 55^{\circ} 10^{\prime} 1^{\prime \prime} \mathrm{W}\right)$ were also visited in April 2011. The gold mining area Sabajo Hills $\left(05^{\circ} 5^{\prime} 38^{\prime \prime} \mathrm{N}, 54^{\circ} 49^{\prime}\right.$ $\left.40^{\prime \prime} \mathrm{W}\right)$ is situated on the borders of the districts Para, Brokopondo, and Sipaliwini (Figure 1), and was also surveyed in both July 2011and June 2012 .

\section{Sand fly collection and species identification}

Sand flies were collected using a total of six CDC light traps. The traps were set for four consecutive nights from $18.00 \mathrm{~h}$ to $07.00 \mathrm{~h}$, one to two meters aboveground. In the villages, the traps were placed at peridomestic sites, in dog kennels, chicken coops, and around agricultural plots. In the gold mining locations, the traps were mainly placed in the forest and in animal burrows, far from human residences.

The collected sand flies were sedated by placing them on ice, and males and females were separated. The males were stored in $70 \%$ alcohol, then mounted in Berlese's fluid. The females were stored in Angero $\mathrm{NA}^{\mathrm{Tm}}$ (Mallinckrodt Baker, USA) conservation buffer in preparation for DNA extraction. The sand flies were categorized by species according to the classification system of Young and Duncan [16] by examination of the spermatecea (females) and the external genitalia (males).

\section{DNA extraction}

Five to ten females of the same species were pooled for DNA extraction in $1 \mathrm{~mL}$ L6 lysis buffer consisting of $50 \mathrm{mM}$ Tris- $\mathrm{HCl}$ (Boehringer, Ingelheim, Ridgefield, CT, USA), $5 \mathrm{M}$ guSCN (Fluka, Buchs, Switzerland), 20 mM EDTA (Merck, Darmstadt, Germany), and 0.1\% Triton-X-100 (Packard, Downers Grove, IL, USA), using a protocol described by Boom et al. [17]. In brief, the sand flies were disrupted by shaking for $3 \mathrm{~min}$ with a 5 -mm stainless steel bead in a mini-bead beater-16 model 607 (Biospec Products, Bartlesville, OK, USA). The DNA was trapped by the addition of $30 \mu \mathrm{L}$ silica gel (Sigma, St. Louis, MO, USA) to the homogenates, mixing for $5 \mathrm{~min}$, and centrifugation for $15 \mathrm{sec}$ at $12,000 \times \mathrm{g}$. The silica pellet was collected, and washed repeatedly with L2 wash buffer (50 mM Tris- $\mathrm{HCl}$ (Boehringer, Ingelheim, Ridgefield, CT, USA), $5 \mathrm{M}$ guSCN (Fluka), 70\% ethanol, and acetone. Finally, the DNA was eluted in $50 \mu \mathrm{L}$ TE buffer (Tris EDTA buffer, $100 \times$ concentrated Sigma) and stored at $-20^{\circ} \mathrm{C}$ until analysis.

\section{Detection of Leishmania DNA}

Leishmania-specific DNA was detected by subjecting the DNA samples to quantitative real time PCR (qPCR) according to a protocol described by van der Meide et al. [18], with slight modifications. Briefly, each amplification reaction contained $2.5 \mu \mathrm{L}$ of isolated DNA/RNA sample and was added to $22.5 \mu \mathrm{L}$ amplification mix containing $1 \times$ mastermix (BioRad, Hercules, CA, USA), $0.8 \mu \mathrm{M}$ each of $18 \mathrm{SF}$ and 18SR primer, and $0.2 \mu \mathrm{M}$ FAM taqman probe. Amplification and real-time measurements were performed in the BioRad opticon minicycler (Biorad, Hercules, CA, USA), under the following conditions: $10 \mathrm{~min}$ at $50^{\circ} \mathrm{C}, 5 \mathrm{~min}$ at $95^{\circ} \mathrm{C}$, followed by 45 cycles of $30 \mathrm{sec}$ at $95^{\circ} \mathrm{C}$, and $45 \mathrm{sec}$ at $60^{\circ} \mathrm{C}$. The samples were compared to a 10 -fold $L$. donovani DNA dilution series ranging from 10 to $10^{7}$ parasites per reaction.

\section{Identification of Leishmania species}

The infecting Leishmania species were identified using a polymerase chain reaction-restriction fragment length polymorphism (PCR-RFLP) assay described by Marfurt et al. [19]. In each PCR run, DNA from L. (V.) guyanensis (M4147), L. (V.) braziliensis, L. (L.) amazonensis (LTB 16), and L. (V.) naiffi (L2204) were included as references. The PCR products were incubated for $2 \mathrm{~h}$ at $37^{\circ} \mathrm{C}$ with the restriction enzyme HaeIII, after which the resulting restriction digestions were analyzed on a $2 \%$ agarose (Sphaero Q, Burgos Spain) gel. Fragments were visualized under UV light. 


\section{Results}

\section{Characteristics of collected sand flies according to site of collection}

Altogether, 2,743 sand flies were collected in the seven collection sites, including 1,740 males and 1,003 females (Table 1). In the district of Sipaliwini, 1,603 and 244 sand flies were captured in the gold mining areas Merian and Benzdorp, respectively, and 13 in the Maroon village of Pikinslee (Table 1). In the Brokopondo district, 250 and 23 sand flies were collected in the gold mining areas at Klaaskreek and Brokopondo Centrum, respectively, and 29 in Maroon villages at Brownsweg (Table 1). At the gold mining area Sabajo Hills, 581 sand flies were captured (Table 1). Thus, approximately twice as many sand flies were captured in the most inward located district of Sipaliwini $(1,830)$ when compared to the more northern locations in Brokopondo and Sabajo Hills (883). Notably, most of the sand fly captures had been performed during the short dry season (February-March) and the subsequent long rainy season (April-July) (Table 1).

\section{Characteristics of collected sand fly species}

A total of 154 flies was damaged during capture, mounting, or transportation and could not be identified. The remainder could be categorized in 34 species (Table 1 ), including 4 that were new for Suriname (46 specimens of Lu. aragaoi, 34 of Lu. ayrozai, 12 of Lu. damascenoi, and 2 of $L u$. sordellii). The most abundant species were Lu. trichopyga (about one-third of the total number of captured flies), as well as Lu. infraspinosa, Lu. ubiquitalis, and $L u$. innini, each of which comprised roughly $10 \%$ of the total catch (Table 1). About $5 \%$ of the collected sand flies could be classified as Lu. squamiventris sensu lato and $3 \%$ as Lu. davisi (Table 1). Approximately 4, 2, and $0.5 \%$ of the catch comprised Lu. umbratilis, Lu. flaviscutellata, and Lu. whitmani, sand fly species that had previously been described as possible vectors in Suriname (Table 1).

More than $90 \%$ of the 122 sand fly specimens belonging to Lu. umbratilis - the proven vector of L. (V.) guyanensis was collected at Merian and Sabajo Hills (Table 1), and almost three-quarters of the 50 specimens belonging to the species Lu. flaviscutellata - the proven vector of $L$. (L.) amazonensis - at Merian (Table 1). On the other hand, Lu. Whitmani, another sand fly species that represents a vector of $L$. (V.) guyanensis, comprised only $0.4 \%$ of the total catch of 2,743 specimens (Table 1 ).

The highest sand fly species diversity was found in the forested locations Sabajo Hills, Merian, and Benzdorp where, 27, 25, and, 20 different species, respectively, were encountered (Table 1). No sand flies were captured near the camps and roads at the gold mining plots of Brokopondo Centrum. The same held true for human residences and stables for domestic animals in or around the villages of Pikinslee and Brownsweg. Only in a dense forested area 1 to 2 meters from a small settlement near Brownsweg, some specimens of Lu. ubiquitalis were captured.

\section{Presence of Leishmania DNA}

Twenty percent of the female sand flies was analyzed by qPCR. One female specimen of the species Lu. squamiventris (s.l.) that was captured at Sabajo Hills and that had visibly taken a blood meal, was positive for $L$. (V.) braziliensis (Table 2). The other sand fly species found positive for Leishmania parasites were from pooled samples of Lu. umbratilis, Lu. ininii, and Lu. trichopyga. These flies were captured at Sabajo Hills and/or Merian (Table 2), but the Leishmania parasites they carried within them could not be identified due to too low or insufficient amounts of DNA.

\section{Discussion}

Although the Leishmania species present in Suriname have been documented, it is still unknown which sand fly vectors are responsible for their transmission. The present study is the first on the sand fly fauna Suriname in almost thirty years, and provides a comprehensive and updated list of sand fly species in different foci of cutaneous leishmaniasis in the country. Four new records for Suriname have been identified (Lu. aragaoi, Lu. ayrozai, Lu.sordellii, and Lu. damascenoi), and four sand fly species infected with Leishmania parasites are reported (Lu. squamiventris (s.l.) with L. (V.) braziliensis, and Lu. umbratilis, Lu. ininii, Lu trichopyga with Leishmania spp.).

The number of sand fly species collected in this study (34) is close to the number (39) described by Burgos \& Hudson [20]. However, the latter number was compiled from collections in thirty different localities, whereas that of the present study was based on numbers encountered in seven foci of cutaneous leishmaniasis in Suriname. These locations were selected in order to increase the likelihood of catching sand flies involved in the transmission of the disease in the country. For the same reason, most surveys were carried out during the months of high and medium rainfall (February through July), when the majority of infections occur (unpublished data, Dermatology Service Paramaribo). These observations may account for the relatively high number of sand fly specimens and species collected in the present study, and the greater numbers captured in forested areas than in villages or camping sites. Notably, infections with $L$ $(V$.$) guyanensis - as mentioned above, the main infecting$ Leishmania species in Suriname - typically occur in the hinterland during the rainy seasons [1].

One of the species found for the first time in Suriname was $L u$. ayrozai. This sand fly is a proven vector of $L$. (V.) naiffi in Brazil $[9,21]$ and of $L$. (V.) braziliensis in 
Table 1 Sand fly species collected at different foci of cutaneous leishmaniasis in the hinterland of Suriname between February 2011 and March 2013

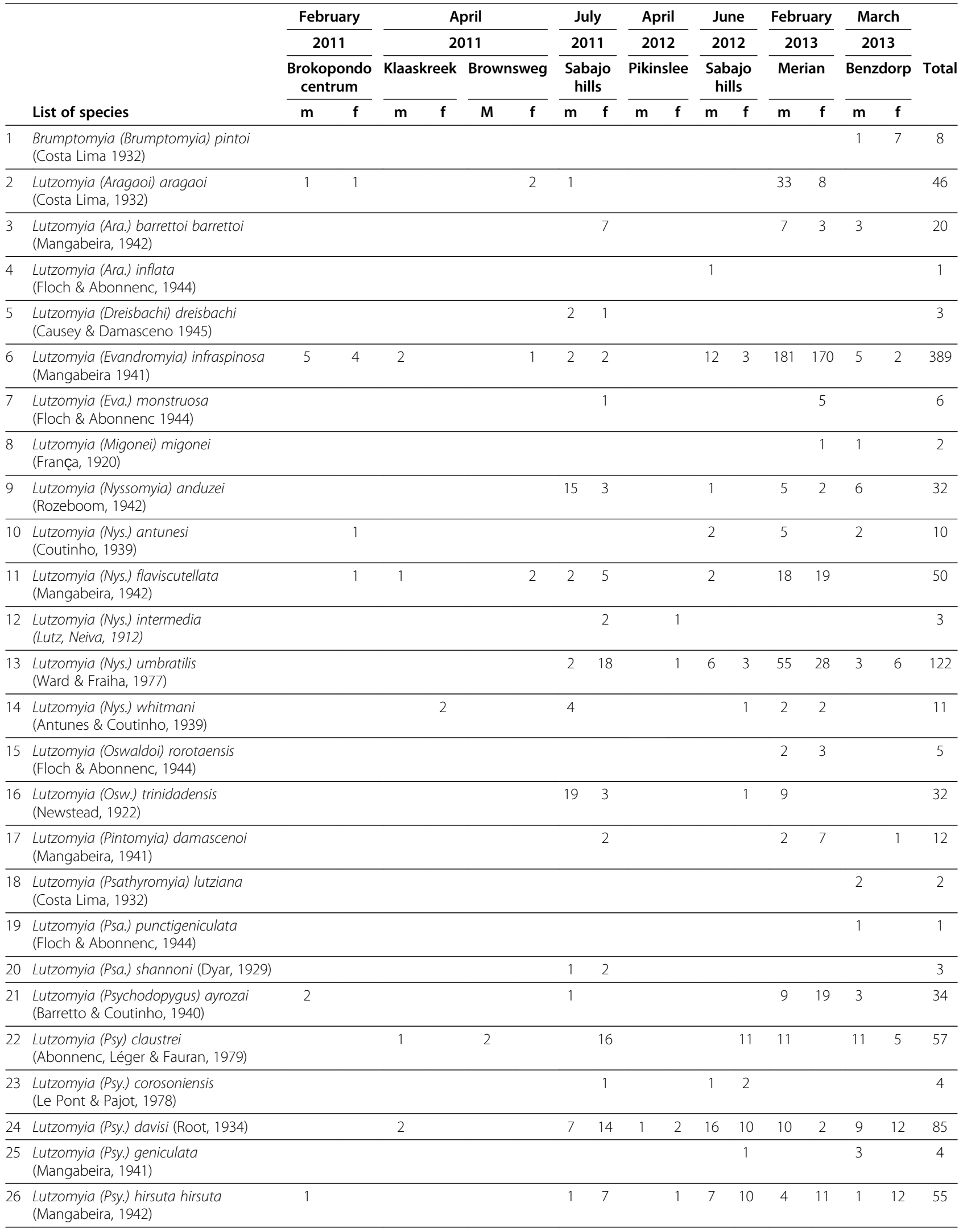


Table 1 Sand fly species collected at different foci of cutaneous leishmaniasis in the hinterland of Suriname between February 2011 and March 2013 (Continued)

\begin{tabular}{|c|c|c|c|c|c|c|c|c|c|c|c|c|c|c|c|c|c|c|}
\hline 27 & $\begin{array}{l}\text { Lutzomyia (Psy.) paraensis } \\
\text { (Cost Lima, 1941) }\end{array}$ & & & & & & & & & & & & & 3 & & & & 3 \\
\hline 28 & $\begin{array}{l}\text { Lutzomyia (Psy.) squamiventris } \\
\text { sensu lato }\end{array}$ & & & & & & & 7 & 43 & & & 9 & 12 & 37 & 33 & & 2 & 143 \\
\hline 29 & $\begin{array}{l}\text { Lutzomyia (Sciopemyia) fluviatilis } \\
\text { (Floch \& Abonnenc, 1944) }\end{array}$ & & & & & & & & & & & & & 2 & & & & 2 \\
\hline 30 & $\begin{array}{l}\text { Lutzomyia (Sci.) sordellii } \\
\text { (Shannon \& Del Ponte, 1927) }\end{array}$ & & & & & & & & & & & & 2 & & & & & 2 \\
\hline 31 & $\begin{array}{l}\text { Lutzomyia (Trichophoromyia) aurensis } \\
\text { (Mangabeira, 1942) }\end{array}$ & & & & & 1 & & & & & & & & 1 & & & & 2 \\
\hline 32 & $\begin{array}{l}\text { Lutzomyia (Tri.) ininii } \\
\text { (Floch \&Abonnenc, 1943) }\end{array}$ & & & & & & & 65 & 18 & 2 & & 45 & 9 & 26 & 21 & 16 & 16 & 218 \\
\hline 33 & $\begin{array}{l}\text { Lutzomyia (Tri.) ubiquitalis } \\
\text { (Mangabeira, 1942) }\end{array}$ & 5 & 1 & 223 & 19 & 17 & 4 & 6 & & & & 10 & 5 & 8 & & 38 & 16 & 352 \\
\hline 34 & $\begin{array}{l}\text { Lutzomyia (Trichopygomyia )trichopyga } \\
\text { (Floch \& Abonnenc, 1945) }\end{array}$ & & & & & & & 7 & 2 & & & 9 & 3 & 628 & 185 & 21 & 15 & 870 \\
\hline & not identified & 1 & & & & & & 7 & 13 & 3 & 2 & 8 & 70 & 4 & 22 & 4 & 20 & 154 \\
\hline & Total & 15 & 8 & 229 & 21 & 20 & 9 & 149 & 160 & 6 & 7 & 129 & 143 & 1062 & 541 & 130 & 114 & 2743 \\
\hline
\end{tabular}

Bolivia [15]. Lu. innini, Lu. ubiquitalis, Lu. umbratilis, and Lu. flaviscutellata are not new for Suriname. However, Lu. innini comprised almost one-tenth of the total catch in the present study, and a French Guianese study reported on specimens of this sand fly species infected with Leishmania species [11]. And Lu. ubiquitalis, Lu. umbratilis, as well as Lu. flaviscutellata constituted approximately 10,4 , and $1 \%$, respectively, of the total number of captured sand flies, and are proven vectors of L. (V.) lainsoni [21], L. (V.) guyanensis [9], and L. (L.) amazonensis [9], respectively. Together, these findings are well in agreement with the identification of the various Leishmania species as causative agents of leishmaniasis in Suriname [10,12-14], providing a plausible explanation for their presence in the country.

The only Leishmania species that could be identified in a sand fly in the present study was $L$. (V.) braziliensis. This parasite was found in a female specimen of $L u$. squamiventris (s.l.) that is generally considered a vector of L. (V.) naiffi in both French Guiana [11] and Brazil [22]. It was captured at Sabajo Hills in the Brokopondo district where possibly one recreational hunter got infected with $L$. (V.) braziliensis (Lai A Fat, personal communication), and two Dutch soldiers with $L$. (V.) naiffi
[13]. These data suggest that Lu. squamiventris (s.l.) could be a vector of $L(V$.) braziliensis and $L(V$.) naiffi in Suriname, supporting the possible presence of various Leishmania species in the country.

Another noteworthy finding from the current study was the presence of Leishmania DNA in several female specimens of Lu. umbratilis. This observation is in accordance with a previous report [23] mentioning the presence of Leishmania promastigotes in the anterior part of the gut of females of this sand fly species. $L u$. umbratilis is the proven vector of $L$. (V.) guyanensis in French Guiana [24] as well as Brazil and Colombia [15] and a few other areas in the Amazon basin $[9,11]$ including Suriname [10]. Therefore, the detection of Leishmania DNA in specimens of this sand fly species in the current study strengthens its candidacy as a vector for this Leishmania species in Suriname [10]. However, further studies are needed to definitively incriminate the reported sand fly species as vectors for Leishmania. In the present study, only few sandflies were found to carry Leishmania parasites (DNA) and more elaborate studies on this topic must be carried out. It is also important to gather information such as infection rates, infectivity, and the presence of metacyclic forms in the mid gut.

Table 2 Lutzomyia species infected with Leishmamia parasites listed according to sites of collection

\begin{tabular}{|c|c|c|c|c|c|c|c|}
\hline & Benzdorp & Pikinslee & Merian & Brokopondo centrum & Klaaskreek & Brownsweg & Sabajo hills \\
\hline Lu. squamiventris sensu lato & - & - & - & - & - & - & L. (V.) braziliensis \\
\hline Lu. umbratilis & - & - & Leishmania spp. & - & - & - & Leishmania sp \\
\hline Lu. ininii & - & - & - & - & - & - & Leishmania sp \\
\hline Lu. trichopyga & - & - & - & - & - & - & Leishmania sp \\
\hline
\end{tabular}




\section{Conclusions}

In summary, this study is the first to present a comprehensive and updated list of sand fly species in important foci of cutaneous leishmaniasis in Suriname, including four new records and six proven vectors of the five Leishmania species in the country. The abundance and diversity of sand fly species was high in these hightransmission areas, and two sand fly species infected with Leishmania parasites (Lu. squamiventris (s.l.) with L. (V.) braziliensis, and Lu. umbratilis with Leishmania spp.) have been identified.

The abundance and diversity of sand fly species in Suriname corresponds with the apparent increase in Leishmania species in the country. This could be due to more encounters with the vectors as a result of the upsurge in economic activities in the forested hinterland [6]. As shown in the current study, the sand fly vectors are predominantly present in this part of the country. The intensive traveling between Suriname, French Guiana, and Brazil in the gold mining areas may also play an important role in the transmission of leishmaniasis in Suriname [6]. The findings described in the present study contribute to a better understanding of leishmaniasis transmission in Suriname and may aid in the development of programs to control this disease in the country.

\section{Competing interests}

The authors declare that they have no competing interests.

\section{Authors' contributions \\ AK: design of the study, field work, determination of sand flies, molecular analysis, and writing of the manuscript; TS: determination of sand flies, training and advice on catching procedures; AG and AS: catching and determination of sand flies; DM and HS: conception of the study, data analysis, and writing of the manuscript. All authors approved the final version of the manuscript.}

\section{Acknowledgements}

We would like to thank the Medical Mission of Suriname (Medische Zending) for facilitating the trips to the interior of the country. Furthermore, we are grateful for Surgold for arranging the logistics for several of these trips. The Surinamese Bureau of Public Health (Bureau Openbare Gezondheid) is acknowledged for assisting with the field work.

\section{Funding}

This study received financial support from the Netherlands Organization for Scientific Research/Foundation for the Advancement of Tropical Research Science for Global Development (project W016531300; Integrated Programme 'Leishmaniasis in Suriname').

\section{Author details}

${ }^{1}$ Department of Parasitology, Faculty of Medical Sciences, Anton de Kom University of Suriname, Kernkampweg 5, Paramaribo, Suriname. ${ }^{2}$ Instituto Evandro Chagas/EvandroChagas Institute, Belem, PA, Brazil. ${ }^{3}$ National Zoological Collection of Suriname, Anton de Kom University of Suriname, Paramaribo, Suriname. ${ }^{4}$ Department of Entomology, Public Health Service, Ministry of Health, Paramaribo, Suriname. ${ }^{5}$ Department of Pharmacology, Faculty of Medical Sciences, Anton de Kom University of Suriname, Kernkampweg 5, Paramaribo, Suriname. ${ }^{6}$ Koninklijk Instituut voor de Tropen (KIT)/Royal Tropical Institute, KIT Biomedical Research, Parasitology Unit, Amsterdam, The Netherlands.
Received: 8 August 2013 Accepted: 25 October 2013

Published: 4 November 2013

\section{References}

1. World Health Organization: Control of the Leishmaniasis. WHO technical report series 949. Geneva: WHO; 2010.

2. Killick-Kendrick R: The biology and control of phlebotomine sand flies. Clin Dermatol 1999, 17:279-289.

3. Reithinger R, Dujardin JC, Louzir H, Pirmez C, Alexander B, Brooker S: Cutaneous Leishmaniasis. Lancet Inf Dis 2007, 7:581-596.

4. Desjeux P: Leishmaniasis: current situation and new perspectives. Comp Immunol Microbiol Inf Dis 2004, 27:305-318.

5. Romero GAS, Boelaert M: Control of Visceral Leishmaniasis in Latin America: a systematic review. PLoS NTD 2010, 4(1):e584.

6. van der Meide WF, Jensema AJ, Akrum RAE, Sabajo LOA, Lai A, Fat RFM, Lambregts L, Schallig HDFH, van der Paardt M, Faber WR: Epidemiology of cutaneous Leishmaniasis in Suriname: a study performed in. Am J Trop Med Hyg 2008, 79:192-197

7. Algemeen Bureau voor de Statistiek (ABS) (Paramaribo), Conservation International Suriname: Environment Statistics. Issue 286 of Suriname in Cijfers. Paramaribo: Algemeen Bureau voor de Statistiek (ABS); 2012.

8. Flu PC: Die aetiologie der in Surinam vorkommenden sogenannten "Boschyaws" einder der Aleppobeule analogen Erkrankung. Centralb/ Bakt Parasit Kde / 1911, 60:624-637.

9. Rotureau B: Ecology of the Leishmania species in the Guianan ecoregion complex. Am J Trop Med Hyg 2006, 74:81-96.

10. Hudson JE, Young DG: New records of phlebotomines, leishmaniasis and mosquitoes from Suriname. Trans R Soc Trop Med Hyg 1985, 79:418-419.

11. Fouque F, Gaborit P, Issaly J, Carinci R, Gantier JC, Racel C, Dedet JP: Phlebotomine sand flies (Diptera: Psychodidae) associated with changing patterns in the transmission of the human cutaneous Leishmaniasis in French Guiana. Mem Ins O Cruz 2007, 102(1):35-40.

12. van der Meide WF, de Vries HJC, Pratlong F, van der Wal A, Sabajo LOA: First reported case of disseminated cutaneous Leishmaniasis caused by Leishmania (Leishmania) amazonensis infection, Suriname. Emerging Inf Dis 2008, 14(5):857-859.

13. van Thiel PPMA, Gool T, van Kager PA, Bart A: First cases of cutaneous Leishmaniasis caused by Leishmania (Viannia) naiffi infection in Suriname. Am J Trop Med Hyg 2010, 82:588-590.

14. Hu RVPF, Kent AD, Adams ER, van der Veer C, Sabajo LOA, Mans DRA, de Vries HJC, Schallig HDFH, Lai A, Fat RFM: Case report: first case of cutaneous Leishmaniasis caused by Leishmania (Viannia) braziliensis in Suriname. Am J Trop Med Hyg 2012, 86(5):825-827.

15. Maroli M, Feliciangeli MD, Bichaud L, Charrel RN, Grandoni L: Phlebotomine sand flies and the spreading of leishmaniasis and other diseases of public health concern. Med Vet Entomol 2013, 27:123-147.

16. Young DG, Duncan GA: Guide to the identification and geographic distribution of Lutzomyia sand flies in Mexico, the West Indies, Central and South-America (Diptera: Psychodidae). Mem Am Entolomol Inst 1994 54:1-881.

17. Boom R, Sol C, Salimans MM, Jansen CL, Wertheim-van Dillen PM, van der Noordaa J: Rapid and simple method for purification of nucleic acids. J Clin Microbiol 1990, 28:495-503.

18. van der Meide WF, Guerra J, Schoone GJ, Farenhorst M, Coelho L, Faber WR, Peekel I, Schallig HDFH: Comparison between quantitative nucleic acid sequence based amplification, real-time reverse transcriptase PCR and real-time PCR for quantification of Leishmania parasites. J Clin Microbiol 2008, 46:73-78.

19. Marfurt J, Nasereddin A, Niederwieser I, Jaffe C, Beck H, Felger I: Identification and differentiation of Leishmania species in clinical samples by PCR amplification of the miniexon sequence and subsequent restriction fragment length polymorphism analysis. J Clin Microbiol 2003, 41:3147-3153.

20. Burgos AM, Hudson JE: Annotated list of the Phlebotominae (Diptera) of Suriname. Mem Inst O Cruz 1994, 89(2):171-178.

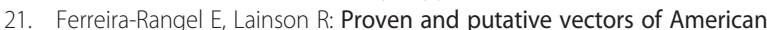
cutaneous Leishmaniasis in Brazil: aspects of their biology and vectorial competence. Mem Inst O Cruz 2009, 104(7):937-954.

22. Naiff RD, Freitas MF, Arias JR, Barrette TV, Momen H, Grimaldi JG: Epidemiological and nosological aspects of Leishmania naiffi Lainson \& Shaw 1989. Mem Inst O Cruz 1991, 86:317-321. 
23. Weijers DJB, Linger R, Man-biting sand flies in Suriname (Dutch Guiana): Phlebotomus anduzei as a possible vector of Leishmania braziliensis. Annals Trop Parasitol 1966, 60:501-508.

24. Le Pont R, Pajot FX, Regeur R: Preliminary observations on the silvatic cycle of leishmaniasis in French Guiana. Trans Roy S Trop Med Hyg 1980, 74(1):133.

doi:10.1186/1756-3305-6-318

Cite this article as: Kent et al.: Studies on the sand fly fauna (Diptera:

Psychodidae) in high-transmission areas of cutaneous leishmaniasis in the

Republic of Suriname. Parasites \& Vectors 2013 6:318.

\section{Submit your next manuscript to BioMed Central and take full advantage of:}

- Convenient online submission

- Thorough peer review

- No space constraints or color figure charges

- Immediate publication on acceptance

- Inclusion in PubMed, CAS, Scopus and Google Scholar

- Research which is freely available for redistribution 